\title{
Circulation
}

American

Heart

Association $_{\circledast}$

\section{Coronary Computed Tomographic Angiography and Risk of All-Cause Mortality and Nonfatal Myocardial Infarction in Subjects Without Chest Pain Syndrome From the CONFIRM Registry (Coronary CT Angiography Evaluation for Clinical Outcomes: An International Multicenter Registry)}

Iksung Cho, Hyuk-Jae Chang, Ji Min Sung, Michael J. Pencina, Fay Y. Lin, Allison M. Dunning, Stephan Achenbach, Mouaz Al-Mallah, Daniel S. Berman, Matthew J. Budoff, Tracy Q. Callister, Benjamin J.W. Chow, Augustin Delago, Martin Hadamitzky, Joerg Hausleiter, Erica Maffei, Filippo Cademartiri, Philipp Kaufmann, Leslee J. Shaw, Gil L. Raff, Kavitha M. Chinnaiyan, Todd C. Villines, Victor Cheng, Khurram Nasir, Millie Gomez and James K. Min

Circulation. 2012;126:304-313; originally published online June 9, 2012; doi: 10.1161/CIRCULATIONAHA.111.081380

Circulation is published by the American Heart Association, 7272 Greenville Avenue, Dallas, TX 75231

Copyright (C) 2012 American Heart Association, Inc. All rights reserved.

Print ISSN: 0009-7322. Online ISSN: 1524-4539

The online version of this article, along with updated information and services, is located on the World Wide Web at:

http://circ.ahajournals.org/content/126/3/304

Data Supplement (unedited) at:

http://circ.ahajournals.org/content/suppl/2012/06/09/CIRCULATIONAHA.111.081380.DC1.html

\footnotetext{
Permissions: Requests for permissions to reproduce figures, tables, or portions of articles originally published in Circulation can be obtained via RightsLink, a service of the Copyright Clearance Center, not the Editorial Office. Once the online version of the published article for which permission is being requested is located, click Request Permissions in the middle column of the Web page under Services. Further information about this process is available in the Permissions and Rights Question and Answer document.
}

Reprints: Information about reprints can be found online at: http://www.lww.com/reprints

Subscriptions: Information about subscribing to Circulation is online at: http://circ.ahajournals.org//subscriptions/ 


\section{Coronary Computed Tomographic Angiography and Risk of All-Cause Mortality and Nonfatal Myocardial Infarction in Subjects Without Chest Pain Syndrome From the CONFIRM Registry (Coronary CT Angiography Evaluation for Clinical Outcomes: An International Multicenter Registry)}

Iksung Cho, MD; Hyuk-Jae Chang, MD, PhD; Ji Min Sung, PhD; Michael J. Pencina, PhD; Fay Y. Lin, MD; Allison M. Dunning, MS; Stephan Achenbach, MD; Mouaz Al-Mallah, MD, MSc; Daniel S. Berman, MD; Matthew J. Budoff, MD; Tracy Q. Callister, MD; Benjamin J.W. Chow, MD; Augustin Delago, MD; Martin Hadamitzky, MD; Joerg Hausleiter, MD; Erica Maffei, MD; Filippo Cademartiri, MD, PhD; Philipp Kaufmann, MD; Leslee J. Shaw, PhD; Gil L. Raff, MD; Kavitha M. Chinnaiyan, MD; Todd C. Villines, MD; Victor Cheng, MD; Khurram Nasir, MD; Millie Gomez, MD; James K. Min, MD; on behalf of the CONFIRM Investigators

Background - The predictive value of coronary computed tomographic angiography (cCTA) in subjects without chest pain syndrome (CPS) has not been established. We investigated the prognostic value of coronary artery disease detection by cCTA and determined the incremental risk stratification benefit of cCTA findings compared with clinical risk factor scoring and coronary artery calcium scoring (CACS) for individuals without CPS.

Methods and Results-An open-label, 12-center, 6-country observational registry of 27125 consecutive patients undergoing cCTA and CACS was queried, and 7590 individuals without CPS or history of coronary artery disease met the inclusion criteria. All-cause mortality and the composite of all-cause mortality and nonfatal myocardial infarction were measured. During a median follow-up of 24 months (interquartile range, 18-35 months), all-cause mortality occurred in 136 individuals. After risk adjustment, compared with individuals without evidence of coronary artery disease by cCTA, individuals with obstructive 2- and 3-vessel disease or left main coronary artery disease experienced higher rates of death and composite outcome $(P<0.05$ for both). Both CACS and cCTA significantly improved the performance of standard risk factor prediction models for all-cause mortality and the composite outcome (likelihood ratio $P<0.05$ for all), but the incremental discriminatory value associated with their inclusion was more pronounced for the composite outcome and for CACS (C statistic for model with risk factors only was 0.71 ; for risk factors plus CACS, 0.75; for risk factors plus CACS plus cCTA, 0.77). The net reclassification improvement resulting from the addition of cCTA to a model based on standard risk factors and CACS was negligible.

\footnotetext{
Received June 13, 2011; accepted May 9, 2012.

From the Division of Cardiology, Severance Cardiovascular Hospital, Seoul, South Korea (I.C., H.C.); Severance Biomedical Science Institute, Seoul, South Korea (H.C.); Department of Research Affairs, College of Medicine, Yonsei University, Seoul, South Korea (J.M.S.); Department of Biostatistics, Boston University, Boston, MA (M.J.P.); Department of Medicine, University of Erlangen, Erlangen, Germany (F.Y.L.); Department of Public Health, Weill Cornell Medicine College and New York Presbyterian Hospital, New York, NY (A.M.D.); Department of Cardiology, University of Giessen, Giessen, Germany (S.A.); Department of Medicine, Wayne State University, Henry Ford Hospital, Detroit, MI (M.A.-M.); Department of Cardiac Imaging, Cedars-Sinai Medical Center, Los Angeles, CA (D.S.B.); Department of Medicine, Harbor UCLA Medical Center, Los Angeles, CA (M.J.B.); Tennessee Heart and Vascular Institute, Hendersonville (T.Q.C.); Department of Medicine and Radiology, University of Ottawa Heart Institute, Ottawa, Ontario, Canada (B.J.W.C.); Capitol Cardiology Association, Albany, NY (A.D.); Division of Cardiology, Deutsches Herzzentrum München, Munich, Germany (M.H., J.H.); Department of Radiology, Erasmus Medical Center University, Rotterdam, Netherlands (E.M., F.C.); Cardiovascular Imaging Unit, Giovanni XXIII Hospital, Monastier di Treviso, Italy (E.M., F.C.); University Hospital, Zurich, Switzerland (P.K.); Division of Cardiology, Emory University School of Medicine, Atlanta, GA (L.J.S.); Department of Cardiology, William Beaumont Hospital, Royal Oak, MI (G.L.R., K.M.C.); Cardiology Service, Walter Reed National Military Medical Center, Bethesda, MD (T.C.V.); Department of Cardiovascular CT, Oklahoma Heart Institute, Tulsa, OK (V.C.); Baptist Health South Florida, Miami, FL (K.N.); Ciccarone Preventive Cardiology Center, Johns Hopkins University, School of Medicine, Baltimore, MD (K.N.); Los Angeles Biomedical Research Institute at Harbor-UCLA, Torrance, CA (K.N.); and Department of Medicine, Cedars-Sinai Heart Institute, Cedars-Sinai Medical Center, Los Angeles, CA (M.G., J.K.M.).
}

Guest Editor for this article was Matthew A. Allison, MD.

The online-only Data Supplement is available with this article at http://circ.ahajournals.org/lookup/suppl/doi:10.1161/CIRCULATIONAHA. 111.081380/-/DC1.

Correspondence to Hyuk-Jae Chang, MD, PhD, Division of Cardiology, Department of Internal Medicine, Yonsei University College of Medicine, 250 Seongsanno Seodaemungu, Seoul, 120-752, Republic of Korea. E-mail hjchang@yuhs.ac

(C) 2012 American Heart Association, Inc. 
Conclusions-Although the prognosis for individuals without CPS is stratified by cCTA, the additional risk-predictive advantage by cCTA is not clinically meaningful compared with a risk model based on CACS. Therefore, at present, the application of cCTA for risk assessment of individuals without CPS should not be justified. (Circulation. 2012;126: 304-313.)
Key Words: asymptomatic
coronary artery calcium
coronary CT angiography
prognosis

$\mathrm{C}$ oronary heart disease (CHD) is the leading cause of morbidity and mortality in developed countries. ${ }^{1}$ Coronary atherosclerosis involves a prolonged asymptomatic developmental phase, with its first manifestations often resulting in sudden cardiac death or nonfatal myocardial infarction (MI). ${ }^{2,3}$ Given the importance of identification of subjects at risk of CHD events, atherosclerosis imaging such as coronary artery calcium scoring (CACS) or carotid intimal-medial thickness for individuals without chest pain syndrome has been advocated recently for use by professional consensus guidelines. ${ }^{4}$ Among the available modalities, CACS, as an atherosclerotic disease surrogate, has been studied the most extensively, with population-based studies demonstrating the ability of CACS findings to improve prognostic risk stratification over clinical risk factor-based scoring in asymptomatic individuals for both sexes and across age groups and ethnicities. ${ }^{5-9}$ Furthermore, CACS has been demonstrated to improve risk restratification above and beyond global risk scores that combine traditional coronary artery disease (CAD) risk factors. ${ }^{10}$

\section{Clinical Perspective on p 313}

Recently, coronary computed tomographic angiography (cCTA) has been introduced as a novel noninvasive atherosclerosis imaging test that may permit diagnostically accurate and prognostically robust assessment of the presence of CAD and risk of CHD events across categories of pretest CAD risk. ${ }^{11,12}$ Although the majority of data to date has focused on symptomatic patients with suspected CAD, cCTA has also been evaluated for use in individuals without chest pain syndrome for an array of potential indications, including equivocal stress test results, preoperative surgical evaluation, assessment of congenital heart disease, and prediction of $\mathrm{CAD}$ events in pretest high-risk patients. However, in these groups without chest pain syndrome, limited data exist to substantiate the prognostic value and clinical usefulness of cCTA over traditional strategies of CAD evaluation. ${ }^{13-17}$

We therefore evaluated in a large international multicenter registry whether CAD assessment by cCTA improved the stratification of risk in individuals without chest pain syndrome, and we examined the incremental value of cCTA findings to clinical risk factor scoring and CACS.

\section{Methods}

\section{Design Overview, Setting, and Participants}

The overall study design of the Coronary CT Angiography Evaluation for Clinical Outcomes: An International Multicenter (CONFIRM) registry has been described previously. ${ }^{18}$ Briefly, the CONFIRM registry is an open-label, international, multicenter observational registry intended to evaluate associations between cCTA findings and their ability to predict mortality and major adverse cardiac events. Strong prognostic value of cCTA in the overall CONFIRM registry has been demonstrated recently. ${ }^{19}$

Between February 2003 and December 2009, 27125 consecutive patients underwent cCTA at 12 centers in 6 countries (United States, Canada, Germany, Switzerland, Italy, and South Korea). Inclusion criteria included the following: (1) age $\geq 18$ years; (2) evaluation by cCTA by CT scanners of $\geq 64$ detector rows; (3) clinical indication for CAD evaluation; (4) interpretable cCTA; and (5) prospective data collection for CAD risk factors. Clinical indications for CONFIRM included evaluation of angina-equivalent symptoms (dyspnea and angina equivalents including pain, tightness, and pressure), dyspnea, preoperative evaluation, and electrophysiological indications (eg, pulmonary vein mapping, left atrial appendage evaluation), as well as evaluation of individuals without chest pain syndrome for assessment of CAD in individuals with congenital heart disease and risk assessment of CAD in individuals with history of peripheral arterial disease, cerebrovascular disease, or multiple CAD risk factors. For the present analysis, we excluded the following: (1) individuals with chest pain (14 063 patients); (2) individuals with unknown symptom status (4685 patients); (3) individuals with a history of prior MI, coronary revascularization, or cardiac transplantation (752 patients); and (4) individuals without follow-up data of mortality or cCTA findings (35 patients). Therefore, 7590 individuals without chest pain syndrome were included for the final primary efficacy analyses. For analyses of the composite end point of death and nonfatal MI, we included only the 4870 individuals at 7 centers that performed comprehensive ascertainment of nonfatal MI. The study protocol was approved by the institutional review boards of all centers, and, when required, all patients provided written informed consent.

\section{Data Acquisition and Image Analysis}

All testing, data acquisition, and image postprocessing for cCTA and CACS in the CONFIRM cohort were in accordance with the Society of Cardiovascular Computed Tomography guidelines on cCTA acquisition..$^{20,21}$ CACS studies and cCTAs were uniformly acquired by multi-detector row CT scanners of $\geq 64$ rows. Radiation dose reduction strategies, including prospective ECG-gated axial acquisition or ECG-gated tube-current modulation, and tube voltage reduction were employed by the decision of the performing providers when clinically feasible. CACS was measured with the use of the scoring system described previously by Agatston et al. ${ }^{22}$ On the basis of the CACS, participants were categorized in the following manner; 0,1 to 100,101 to 400 , and $>400$.

In each coronary segment, coronary atherosclerosis was defined as any tissue structures $>1 \mathrm{~mm}^{2}$ that existed either within the coronary artery lumen or adjacent to the coronary artery lumen that could be discriminated from surrounding pericardial tissue, epicardial fat, or the vessel lumen itself. Each identified lesion was examined with the use of maximum intensity projection and multiplanar reconstruction techniques along multiple longitudinal axes and in the transverse plane. Each site interpreted cCTA in accordance with Society of Cardiovascular Computed Tomography guidelines. ${ }^{20,21}$ A 16segment coronary artery tree model was employed (left main; proximal, mid, and distal left anterior descending artery; first and second diagonal branches of the left anterior descending coronary artery; proximal and distal left circumflex artery; first and second obtuse marginal branches of the left circumflex artery; proximal, mid, and distal right coronary artery; posterior descending artery; and posterolateral branch [left or right]). CAD was defined as the presence of any plaque. CAD extent and severity were graded by various methods: First, obstructive CAD was defined when coronary 
Table 1. Baseline Characteristics of the Study Population According to the Existence of Obstructive CAD Evidenced by cCTA

\begin{tabular}{|c|c|c|c|c|}
\hline \multirow[b]{2}{*}{ Variable } & \multirow[b]{2}{*}{ Total $(n=7590)$} & \multicolumn{2}{|c|}{ Obstructive $\mathrm{CAD}^{*}$ on cCTA } & \multirow[b]{2}{*}{$P$} \\
\hline & & Absent $(n=5674)$ & Present $(n=1916)$ & \\
\hline Mean age, y & $58 \pm 12$ & $57 \pm 12$ & $64 \pm 10$ & $<0.001$ \\
\hline Sex (male) & $4623(60.9)$ & $3343(58.9)$ & $1280(66.8)$ & $<0.001$ \\
\hline Hypertension & 3572 (47.5) & 2459 (43.9) & $1113(58.5)$ & $<0.001$ \\
\hline Diabetes mellitus & $1103(14.6)$ & $669(11.9)$ & $434(22.7)$ & $<0.001$ \\
\hline Current smoking & $1247(16.5)$ & $841(14.9)$ & $406(21.3)$ & $<0.001$ \\
\hline Body mass index, $\mathrm{kg} / \mathrm{m}^{2}$ & $27 \pm 5$ & $27 \pm 5$ & $27 \pm 5$ & 0.289 \\
\hline Dyslipidemia & $4721(62.7)$ & $3372(60.1)$ & $1349(70.7)$ & $<0.001$ \\
\hline Total cholesterol, $\mathrm{md} / \mathrm{dL}$ & $200 \pm 53$ & $194 \pm 48$ & $190 \pm 50$ & 0.057 \\
\hline HDL cholesterol, mg/dL & $53 \pm 17$ & $54 \pm 17$ & $49 \pm 16$ & $<0.001$ \\
\hline LDL cholesterol, mg/dL & $118 \pm 39$ & $119 \pm 38$ & $115 \pm 42$ & 0.048 \\
\hline Family history of premature CHD & $2592(34.9)$ & $1848(33.3)$ & $744(39.3)$ & $<0.001$ \\
\hline FRS 10-y risk categories† & & & & $<0.001$ \\
\hline Low $(<10)$ & 3235 (48.2) & $2797(55.6)$ & $438(26.2)$ & \\
\hline Low-intermediate (10-15) & $1585(23.6)$ & $1171(23.3)$ & $414(24.8)$ & \\
\hline High-intermediate (16-20) & $622(9.3)$ & $420(8.3)$ & $202(12.1)$ & \\
\hline High $(>20)$ & $1264(18.8)$ & $647(12.9)$ & $617(36.9)$ & \\
\hline CACS $\ddagger$ & & & & $<0.001$ \\
\hline 0 & $1971(44.9)$ & $1,875(52.2)$ & $96(12.0)$ & \\
\hline $1-100$ & $1119(25.5)$ & $964(26.8)$ & $155(19.4)$ & \\
\hline $101-400$ & $732(16.7)$ & $499(13.9)$ & $233(29.2)$ & \\
\hline$>400$ & $568(12.9)$ & $255(7.1)$ & $313(39.3)$ & \\
\hline
\end{tabular}

\footnotetext{
Continuous values are mean \pm SD; categorical values are number (\%). CAD indicates coronary artery disease; cCTA, coronary computed tomographic angiography; HDL, high-density lipoprotein; LDL, low-density lipoprotein; CHD, coronary heart disease; FRS, Framingham Risk Score; and CACS, coronary artery calcium score.

${ }^{*}$ Obstructive CAD was defined when coronary artery segments exhibited plaque with a luminal diameter stenosis $\geq 50 \%$.

†FRS 10 -y risk was available in 6706 patients.

¥CACS was available in 4390 patients.
}

artery segments exhibited plaque with a luminal diameter stenosis $\geq 50 \%$, and nonobstructive CAD was defined when coronary artery segments exhibited plaque with a luminal diameter stenosis $>0 \%<50 \%$. Individuals manifesting obstructive CAD were further categorized as having 1-, 2-, and 3-vessel disease or left main disease. In addition, coronary artery plaque scores were calculated for overall plaque burden by extent and severity of CAD with the use of a modified Duke prognostic score, segment stenosis score (SSS), and segment involvement score (SIS), as we have described previously. ${ }^{23}$ Detailed methods for calculating modified Duke prognostic CAD score, SSS, and SIS are described in Methods in the onlineonly Data Supplement.

\section{Patient Follow-Up}

Follow-up for all-cause mortality and nonfatal MI was performed by each local institution by a dedicated physician and/or research nurse blinded to the cCTA results. At US sites, ascertainment of death was determined by query of the National Death Index. In non-US sites, ascertainment of death was determined by direct interview and/or telephone contact and/or review of medical records. Additional event ascertainment, including MI, was performed at certain sites by direct interview, telephone contact, or review of medical records.

\section{Statistical Analysis}

Continuous variables are expressed as mean $\pm \mathrm{SD}$, and categorical variables are presented as absolute counts and percentages. Differences between continuous variables were analyzed by Student $t$ test, and those between categorical variables were analyzed by the $\chi^{2}$ test or Fisher exact test, as appropriate. We considered 2 end points: all-cause mortality and a composite of all-cause mortality and nonfatal MI. Cumulative event rates as a function of time and cCTA-diagnosed CAD were calculated with the Kaplan-Meier estimator and compared with the log-rank statistic. The hazards for the association of the various measures of cCTA-diagnosed CAD with the outcomes were calculated with the use of Cox proportional hazards models, first unadjusted and then adjusted for Framingham Risk Score (FRS) risk factors, as follows: age, sex, current smoking, hypertension, dyslipidemia, and diabetes mellitus. For assessment of the added value of CACS and cCTA in risk prediction, we considered the following models. Model I was based on risk factors only. To allow for different strengths of adjustment, we used 2 forms of risk factors: The first one included categories of the published FRS (low [ $<10 \%]$, low-intermediate [10-15\%], high-intermediate [16$20 \%]$, high $[>20 \%]$ ), and the second incorporated the aforementioned individual risk factors. In model II, we added CACS expressed as 4 categories $(0,1-100,101-400,>400)$ to the models containing Framingham risk factors. Model III added cCTAdiagnosed number of involved vessels (NIV) (none, nonobstructive CAD, obstructive 1-vessel disease, 2-vessel disease, or 3-vessel disease or left main CAD) to model II. Model IV added the Duke CAD prognostic index to model II. Model V added cCTA-diagnosed SSS, and model VI added cCTA-diagnosed SIS to model II. From the Cox models, hazard ratios (HRs) and $95 \%$ confidence intervals (CIs) were calculated.

The statistical significance of the contribution of the added variable was assessed with the likelihood ratio test, following recent 
Table 2. Risk of All-Cause Mortality According to FRS, CACS, and cCTA

\begin{tabular}{|c|c|c|c|c|c|c|c|c|}
\hline \multirow[b]{2}{*}{ Variable } & \multicolumn{4}{|c|}{ Unadjusted } & \multicolumn{4}{|c|}{$\begin{array}{l}\text { Adjusted for Individual } \\
\text { Framingham Risk Factors* }\end{array}$} \\
\hline & $\mathrm{n} \dagger$ & $\mathrm{HR}$ & $95 \% \mathrm{Cl}$ & $P$ & $\mathrm{n}$ & $\mathrm{HR}$ & $95 \% \mathrm{Cl}$ & $P$ \\
\hline FRS & 6706 & & & $<0.001 \ddagger$ & & & & \\
\hline Low $(<10)$ & 3235 & 1.0 & & & & & & \\
\hline Low-intermediate (10-15) & 1585 & 1.32 & $0.81-2.15$ & 0.262 & & & NA & \\
\hline High-intermediate (16-20) & 622 & 1.86 & $1.03-3.36$ & 0.040 & & & & \\
\hline $\operatorname{High}(>20)$ & 1264 & 2.57 & $1.67-3.95$ & $<0.001$ & & & & \\
\hline CACS & 4390 & & & $<0.001 \ddagger$ & 3900 & & & $<0.001 \ddagger$ \\
\hline 0 & 1971 & 1.0 & & & 1765 & 1.0 & & \\
\hline $1-100$ & 1119 & 1.66 & $0.85-3.25$ & 0.142 & 987 & 1.05 & $0.52-2.12$ & 0.895 \\
\hline $101-400$ & 732 & 2.43 & $1.23-4.83$ & 0.011 & 644 & 1.44 & $0.70-2.95$ & 0.321 \\
\hline$>400$ & 568 & 4.97 & $2.68-9.21$ & $<0.001$ & 504 & 2.38 & $1.19-4.74$ & 0.014 \\
\hline \multicolumn{9}{|l|}{ cCTA } \\
\hline Presence of obstructive CAD & 7590 & & & & 6706 & & & \\
\hline None or nonobstructive CAD & 5674 & 1.0 & & & 5035 & 1.0 & & \\
\hline Obstructive CAD & 1916 & 2.72 & $1.94-3.80$ & $<0.001$ & 1671 & 1.70 & $1.20-2.41$ & 0.003 \\
\hline No. of involved vessels & 7590 & & & $<0.001 \ddagger$ & 6706 & & & $<0.001 \ddagger$ \\
\hline None & 2844 & 1.0 & & & 2551 & 1.0 & & \\
\hline Nonobstructive CAD & 2830 & 2.04 & $1.25-3.35$ & 0.002 & 2484 & 1.19 & $0.71-1.98$ & 0.511 \\
\hline 1-vessel disease & 1109 & 2.77 & $1.59-4.83$ & $<0.001$ & 953 & 1.42 & $0.80-2.53$ & 0.232 \\
\hline 2-vessel disease & 494 & 4.61 & $2.53-8.42$ & $<0.001$ & 435 & 2.20 & $1.19-4.16$ & 0.013 \\
\hline 3-vessel disease or left main CAD & 313 & 7.91 & $4.41-14.21$ & $<0.001$ & 283 & 2.91 & $1.55-5.47$ & 0.001 \\
\hline Duke index (per score increased) & 7590 & 1.36 & $1.26-1.47$ & $<0.001 \ddagger$ & 6706 & 1.20 & $1.10-1.31$ & $<0.001 \ddagger$ \\
\hline SSS (per segment severity) & 7590 & 1.11 & $1.07-1.13$ & $<0.001 \ddagger$ & 6706 & 1.06 & $1.02-1.09$ & $0.001 \ddagger$ \\
\hline SIS (per segment involved) & 7590 & 1.15 & $1.10-1.21$ & $<0.001 \ddagger$ & 6706 & 1.06 & $0.99-1.12$ & 0.058 \\
\hline
\end{tabular}

FRS indicates Framingham Risk Score; CACS, coronary artery calcium score; CCTA, coronary computed tomographic angiography; HR, hazard ratio; Cl, confidence interval; CAD, coronary artery disease; Duke index, Duke CAD prognostic index; SSS, segment stenosis score; SIS, segment involvement score; and NA, not applicable.

*Individual Framingham risk factors included age, sex, hypertension, diabetes mellitus, current smoking, and dyslipidemia.

†Among the study cohort with cCTA data, FRS was available in 6706 patients; CACS in 4390; and both FRS and CACS in 3900.

$\ddagger P$ value for trend.

recommendations. ${ }^{24}$ To evaluate model discrimination, we calculated the $\mathrm{C}$ statistics for the aforementioned models. ${ }^{25,26} \mathrm{We}$ used a 2.5-year horizon for the analyses, but not all subjects had follow-up completed until 2.5 years. To address the issue of censored data, the prospective form of net reclassification improvement (NRI) proposed by Pencina et al ${ }^{27,28}$ was employed. Detailed methods to calculate NRI are described in Methods in the online-only Data Supplement. We defined 2.5-year risk categories as follows: (1) $0 \%$ to $<1.5 \%$; (2) $1.5 \%$ to $<5 \%$; and (3) $\geq 5 \%$; these categories were derived from Framingham 10-year risk of CHD categories ( $0 \%$ to $<6 \% ; 6 \%$ to $<20 \% ; \geq 20 \%$ ). A standard bootstrap method was used to generate the corresponding CIs for this estimate. $P<.05$ was considered statistically significant. The CIs of Cox regression, $\mathrm{C}$ statistics, and NRI are $95 \%$ throughout this article. All analyses were performed with SAS (version 9.1.3; SAS Institute Inc, Cary, NC).

\section{Results}

\section{Clinical Characteristics and Outcomes}

Overall, the study population consisted of 7590 individuals without chest pain syndrome; $61 \%$ were male, and the mean age was $58 \pm 12$ years. Among the study cohort, 2830 had nonobstructive CAD, and 1916 (25.2\%) had obstructive CAD: 1-vessel disease, 1109 (14.6\%); 2-vessel disease, 494
(6.5\%); 3-vessel disease or left main disease, 313 (4.1\%). Patients with obstructive CAD were generally older, were male, and had a higher prevalence of hypertension, diabetes mellitus, and dyslipidemia (all $P<0.001$ ) (Table 1). FRS was available in 6706 patients, and CACS was available in 4390 patients. Among them, patients with obstructive CAD had higher FRS and CACS $(P<0.001$ for both).

During the median follow-up duration of 24 months (25th to 75 th percentile, $18-35$ months), there were 136 deaths by any cause among 7590 individuals. The overall cumulative 2.5 -year mortality rate was $2.3 \%$ (CI, $1.9-2.7 \%$ ). The 2.5 year mortality rate of individuals with obstructive CAD (4.1\%; CI, 3.2-5.2\%) was higher than that of those without obstructive CAD (1.7\%; CI, 1.3-2.1\%) (log-rank $P<0.001$ ). Among individuals who had follow-up data of both nonfatal MI and all-cause mortality $(n=4870), 74$ events (14 nonfatal MIs and 60 deaths) were reported. The overall cumulative 2.5-year composite outcome rate was $2.2 \%$ (CI, 1.7-2.7\%). The cumulative 2.5-year composite outcome rate of individuals with obstructive CAD (4.6\%; CI, 3.2-6.6\%) was higher than that of those without obstructive CAD (1.6\%; CI, $1.2-2.2 \%)$ (log-rank $P<0.001$ ). 

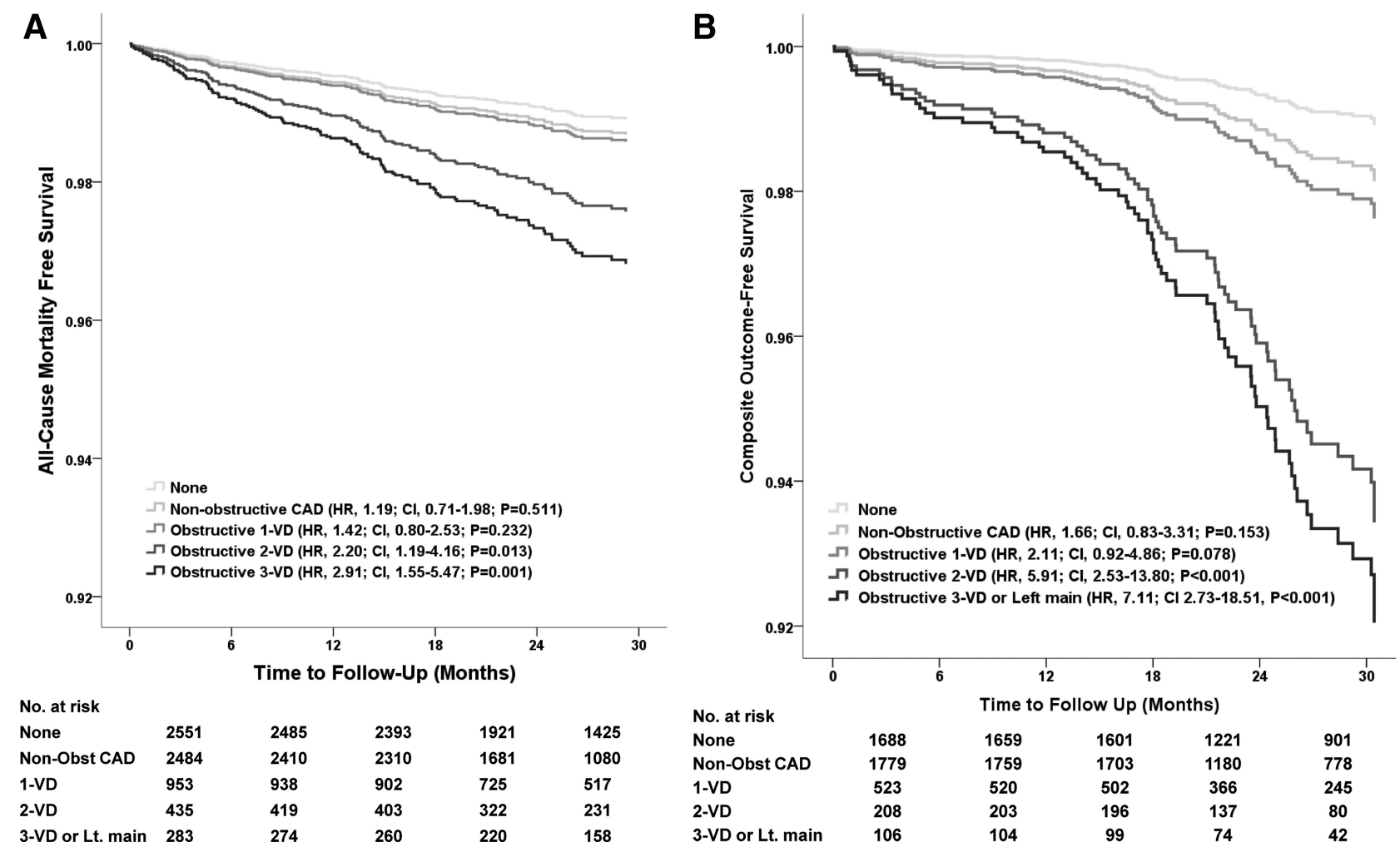

$\begin{array}{llllll}\text { No. at risk } & & & & & \\ \text { None } & 2551 & 2485 & 2393 & 1921 & 1425 \\ \text { Non-Obst CAD } & 2484 & 2410 & 2310 & 1681 & 1080 \\ \text { 1-VD } & 953 & 938 & 902 & 725 & 517 \\ \text { 2-VD } & 435 & 419 & 403 & 322 & 231 \\ \text { 3-VD or Lt. main } & 283 & 274 & 260 & 220 & 158\end{array}$

Figure. A, Adjusted (by Framingham risk factors including age, sex, hypertension, diabetes mellitus, current smoking, and dyslipidemia) all-cause mortality-free survival by number of involved vessels detected by coronary computed tomographic angiography in individuals without chest pain syndrome. B, Adjusted (by Framingham risk factors including age, sex, hypertension, diabetes mellitus, current smoking, and dyslipidemia) composite outcome of all-cause mortality- and nonfatal myocardial infarction-free survival by number of involved vessels detected by coronary computed tomographic angiography in individuals without chest pain syndrome. CAD indicates coronary artery disease; HR, hazard ratio; CI, 95\% confidence interval; Non-Obst, nonobstructive; VD, vessel disease; and Lt, left.

\section{Univariable Cox Models of FRS, CACS, and cCTA}

Compared with individuals with low FRS, increasing hazards for all-cause mortality were observed in relation to increasing FRS $(P<0.001$ for trend), in particular for those with high FRS (HR, 2.57; CI, 1.67-3.95; $P<0.001$ ) (Table 2). Increasing CACS was also associated with increased risk for death $(P<0.001$ for trend), principally for those with CACS 101 to 400 (HR, 2.43; CI, 1.23-4.83; $P=0.011$ ) and CACS $>400$ (HR, 4.97; CI, 2.68-9.21; $P<0.001$ ). By cCTA, compared with those without $\mathrm{CAD}$, the relative hazards for death increased proportionally to CAD extent for nonobstructive CAD (HR, 2.04; CI, 1.25-3.35; $P=0.002)$, obstructive 1-vessel disease (HR, 2.77; CI, 1.59-4.83; P<0.001), obstructive 2-vessel disease (HR, 4.61; CI, 2.53-8.42; $P<0.001$ ), and obstructive 3-vessel disease or left main CAD (HR, 7.91; CI, 4.41-14.21; $P<0.001)$. Similarly, cCTA scores measuring CAD plaque burden, including the Duke CAD prognostic index, SSS, and SIS, were uniformly predictive of incident death $(P<0.001$ for trend, for all).

\section{Multivariable Cox Models of CACS and cCTA}

In multivariable models accounting for individual Framingham risk factors, CACS $>400$ (HR, 2.38; CI, 1.19-4.74; $P=0.014)$ was significantly associated with future death. Similarly, cCTA-based CAD was independently predictive of mortality $(P<0.001$ for trend; Table 2$)$, with individual significant effects observed for obstructive 2-vessel disease (HR, 2.20; CI, 1.19-4.16; $P=0.013$ ) and obstructive 3-vessel disease or left main CAD (HR, 2.91; CI, 1.55-5.47; $P=0.001$ ), as depicted in the Figure, panel A. cCTA CAD plaque burden scores were also independently associated with future death, as measured by the Duke CAD prognostic index and SSS ( $P \leq 0.001$ for trend, for both), as described in Table 2 .

For the composite outcome, cCTA was independently predictive of future death and nonfatal MI for measures of obstructive 2-vessel disease (HR, 5.91; CI, 2.53-13.80; $P<0.001)$ and obstructive 3 -vessel disease or left main CAD (HR, 7.11; CI, 2.73-18.51; $P<0.001$ ), as shown in the Figure, panel B. cCTA CAD plaque burden scores including Duke CAD prognostic index, SSS, and SIS showed an independent association with the composite outcome as well $(P<0.001$ for all) (Table I in the online-only Data Supplement).

\section{Incremental Value of CACS and cCTA for Prediction of Future Mortality and Composite Outcome}

Inclusion of CACS significantly improved the model based on risk factors only; the mortality model likelihood ratio test $P$ value for adding CACS to FRS was $<0.001$ and for adding it to individual risk factors was $<0.001$; the composite outcome model likelihood ratio test $P$ value for adding CACS to FRS was $<0.001$ and for adding it to individual risk factors was $<0.001$ (Table II in the online-only Data Supplement). 
Table 3. C Statistics for Prediction of 2.5-Year Risk of All-Cause Mortality and Composite Outcome of All-Cause Mortality and Nonfatal MI Using Combined Models of Framingham Risk Factors Plus CACS or cCTA

\begin{tabular}{|c|c|c|}
\hline \multirow[b]{2}{*}{ Model } & \multicolumn{2}{|c|}{ C Statistics* } \\
\hline & $\mathrm{FRS}^{*}$ & $\begin{array}{l}\text { Individual Risk } \\
\text { Factors* }\end{array}$ \\
\hline \multicolumn{3}{|l|}{ All-cause mortality $(n=3900)$} \\
\hline Model I: RFs only & $0.62(0.55-0.69)$ & $0.76(0.70-0.83)$ \\
\hline Model II: RFs + CACS & $0.71(0.65-0.77)$ & $0.78(0.65-0.84)$ \\
\hline Model III: RFs+CACS+NIV & $0.73(0.67-0.78)$ & $0.78(0.67-0.84)$ \\
\hline Model IV: RFs+CACS+Duke & $0.72(0.66-0.78)$ & $0.78(0.66-0.84)$ \\
\hline Model V: RFs+CACS+SSS & $0.72(0.66-0.78)$ & $0.78(0.66-0.84)$ \\
\hline Model VI: RFs+CACS+SIS & $0.72(0.66-0.78)$ & $0.78(0.66-0.84)$ \\
\hline \multicolumn{3}{|c|}{$\begin{array}{l}\text { Composite outcome of all-cause } \\
\text { mortality and nonfatal MI }(n=3217)\end{array}$} \\
\hline Model I: RFs only & $0.59(0.52-0.67)$ & $0.71(0.63-0.78)$ \\
\hline Model II: RFs + CACS & $0.71(0.64-0.78)$ & $0.75(0.68-0.81)$ \\
\hline Model III: RFs+CACS+NIV & $0.74(0.66-0.81)$ & $0.77(0.70-0.84)$ \\
\hline Model IV: RFs+CACS+Duke & $0.74(0.67-0.81)$ & $0.76(0.69-0.83)$ \\
\hline Model V: RFs + CACS +SSS & $0.74(0.67-0.81)$ & $0.76(0.69-0.83)$ \\
\hline Model VI: RFs+CACS+SIS & $0.74(0.68-0.81)$ & $0.76(0.69-0.83)$ \\
\hline
\end{tabular}

Values in parentheses are $95 \%$ confidence intervals. MI indicates myocardial infarction; CACS, coronary artery calcium score; cCTA, coronary computed tomographic angiography; FRS, Framingham Risk Score; RFs, risk factors; NIV, number of involved vessels (categorized as none, nonobstructive coronary artery disease, obstructive 1-, 2-, 3-vessel disease or left main coronary artery disease); Duke, Duke coronary artery disease prognostic index; SSS, segment stenosis score; and SIS, segment involvement score.

*Baseline risk factors were entered as a combined score in the FRS column and as individual Framingham risk variables (age, sex, hypertension, diabetes mellitus, current smoking, and dyslipidemia) in the Individual Risk Factors column.

This translated into appreciable increases in model discrimination compared with the model with categorical FRS (from 0.62 to 0.71 for all-cause mortality and from 0.59 to 0.71 for the composite outcome; Table 3), which were attenuated when compared with the model with individual risk factors (from 0.76 to 0.78 for all-cause mortality and from 0.71 to 0.75 for the composite outcome; Table 3 ).

However, the addition of cCTA to a model with Framingham risk factors and CACS did not lead to a significant improvement for all-cause mortality; the likelihood ratio test $P$ value for adding cCTA to FRS plus CACS was 0.423 and for adding it to individual risk factors plus CACS was 0.469 (Table II in the online-only Data Supplement). This translated into modest improvements in discrimination as measured by the change in the $\mathrm{C}$ statistics (at best, this was 0.02 compared with the FRS plus CACS model and $<0.01$ compared with the model with individual risk factors plus CACS; Table 3). For the composite outcome, the addition of cCTA to a model with Framingham risk factors and CACS led to a significant improvement (the likelihood ratio test $P$ value for adding cCTA to FRS plus CACS was $<0.001$ and for adding it to individual risk factors plus CACS was 0.003). The increments of $\mathrm{C}$ statistics were also more promising ( 0.03 com- pared with the FRS plus CACS model and from 0.01 to 0.02 compared with the model with individual risk factors plus CACS; Table 3). However, the increments of $\mathrm{C}$ statistics were minor compared with those for adding CACS to FRS and individual risk factors (0.12 and 0.04, respectively).

As demonstrated in Table 4, the ability of CACS to correctly reclassify individuals from FRS was significant for all-cause mortality and the composite outcome (NRI for adding CACS to FRS was 0.43 and 0.53 , respectively); these values were attenuated when individual risk factors were entered as the baseline model (0.04 and 0.14, respectively). However, the ability of cCTA to correctly reclassify individuals from model II, with a priori established risk categories based on the model with Framingham risk factors plus CACS, was limited. The claim of no effect could not be ruled out on the basis of the $95 \%$ CIs. The NRI was particularly weak numerically for all-cause mortality, at $\leq 0.05$, and was modestly better for the composite outcome (maximum 0.09; Table 4).

\section{Discussion}

\section{Principal Findings}

In this international multicenter study of individuals without chest pain syndrome, increasing extent and severity of CAD, as measured by CACS and cCTA, independently and proportionately stratify risk of future death and a composite outcome of death and nonfatal MI. Importantly, the added risk-predictive advantage by cCTA measures of CAD is imperceptible compared with Framingham risk factors plus CACS. These present data have major implications for the decision to perform cCTA in subjects without chest pain syndrome and suggest that use of CACS may be sufficient for risk stratification of this population.

\section{The Role of CACS for Risk Stratification}

CACS has been known to provide powerful prognostic information in multiple population-based studies for both sexes and multiple ethnic groups. ${ }^{5-8}$ The Multi-Ethnic Study of Atherosclerosis (MESA), conducted in 6722 asymptomatic subjects as a representative multiethnic US population, demonstrated an incremental prognostic value of CACS over traditional risk factors by comparison of the areas under the receiver operating characteristic curves. ${ }^{8}$ More recently, Polonsky et $\mathrm{al}^{10}$ showed that addition of CACS to a prediction model based on traditional risk factors significantly improved the stratification of future risk of CHD in the same cohort by using NRIs $(0.25$; CI, $0.16-0.34 ; P<0.001)$ and integrated discrimination improvement $(0.026 ; P<0.001)$. Similarly, the Heinz Nixdorf Recall Study showed that CACS successfully reclassified and improved risk prediction of "hard" CHD events including nonfatal MI and coronary death over traditional risk factors. ${ }^{9}$ Given these findings, the use of CACS for risk stratification of an asymptomatic population has been advocated by numerous professional guidelines. ${ }^{4,29,30}$

\section{Previous cCTA Registry Data}

Recently, the use of cCTA has been advocated as a potentially valuable atherosclerosis imaging tool for risk stratification. ${ }^{12,31}$ Several studies have explored the prognostic value of cCTA, primarily limited to symptomatic populations. ${ }^{23,32}$ 
Table 4. Reclassification of 2.5-Year Risk of All-Cause Mortality and Composite Outcome Using Multivariate Risk Prediction Model With and Without Inclusion of cCTA

\begin{tabular}{|c|c|c|c|c|c|c|}
\hline \multirow[b]{2}{*}{ Model } & \multicolumn{3}{|c|}{ FRS $^{*}$} & \multicolumn{3}{|c|}{ Individual Risk Factors* } \\
\hline & NRI† (95\% Cl) & $\begin{array}{l}\text { Proportion } \\
\text { of Events } \\
\text { Correctly } \\
\text { Reclassified }\end{array}$ & $\begin{array}{l}\text { Proportion of } \\
\text { Nonevents } \\
\text { Correctly } \\
\text { Reclassified }\end{array}$ & NRI† (95\% Cl) & $\begin{array}{l}\text { Proportion } \\
\text { of Events } \\
\text { Correctly } \\
\text { Reclassified }\end{array}$ & $\begin{array}{l}\text { Proportion of } \\
\text { Nonevents } \\
\text { Correctly } \\
\text { Reclassified }\end{array}$ \\
\hline \multicolumn{7}{|l|}{ All-cause mortality $(n=3900)$} \\
\hline \multicolumn{7}{|c|}{ Compared with model I (baseline RFs) } \\
\hline Model II: RFs+CACS & $0.43(0.25$ to 0.64$)$ & 0.00 & 0.43 & $0.04(-0.08$ to 0.16$)$ & 0.08 & -0.04 \\
\hline Model III: RFs+CACS+NIV & 0.45 (0.26 to 0.64$)$ & 0.05 & 0.40 & 0.06 ( -0.08 to 0.22$)$ & 0.10 & -0.04 \\
\hline Model IV: RFs+CACS+Duke & $0.47(0.27$ to 0.67$)$ & 0.04 & 0.42 & $0.00(-0.10$ to 0.12$)$ & 0.04 & -0.04 \\
\hline Model V: RFs+CACS+SSS & $0.48(0.27$ to 0.68$)$ & 0.03 & 0.44 & $0.03(-0.09$ to 0.16$)$ & 0.08 & -0.05 \\
\hline Model VI: RFs+CACS+SIS & $0.49(0.28$ to 0.70$)$ & 0.05 & 0.44 & $0.04(-0.08$ to 0.17$)$ & 0.08 & -0.04 \\
\hline \multicolumn{7}{|c|}{ Compared with model II (RFs+CACS) } \\
\hline Model III: RFs+CACS+NIV & $0.01(-0.04$ to 0.07$)$ & 0.05 & -0.04 & $0.03(-0.06$ to 0.17$)$ & 0.03 & 0.01 \\
\hline Model IV: RFs+CACS+ Duke & $0.03(-0.02$ to 0.10$)$ & 0.05 & -0.02 & $-0.03(-0.10$ to 0.05$)$ & -0.03 & 0.00 \\
\hline Model V: RFs+CACS+SSS & $0.04(-0.01$ to 0.09$)$ & 0.03 & 0.01 & $-0.01(-0.06$ to 0.04$)$ & -0.01 & 0.00 \\
\hline Model VI: RFs+CACS+SIS & 0.05 (0.01 to 0.09$)$ & 0.05 & 0.00 & $0.00(0.00$ to 0.00$)$ & 0.00 & 0.00 \\
\hline \multicolumn{7}{|l|}{$\begin{array}{l}\text { Composite outcome of all-cause } \\
\text { mortality and nonfatal } \mathrm{MI}(\mathrm{n}=3217)\end{array}$} \\
\hline \multicolumn{7}{|c|}{ Compared with model I (baseline RFs) } \\
\hline Model II: RFs+CACS & $0.53(0.29$ to 0.77$)$ & 0.12 & 0.42 & $0.14(-0.03$ to 0.33$)$ & 0.17 & -0.03 \\
\hline Model III: RFs+CACS+NIV & 0.51 (0.32 to 0.71$)$ & 0.16 & 0.34 & 0.19 (0.03 to 0.37$)$ & 0.17 & 0.03 \\
\hline Model IV: RFs+CACS+Duke & $0.58(0.35$ to 0.81$)$ & 0.20 & 0.37 & 0.21 (0.03 to 0.39$)$ & 0.21 & 0.00 \\
\hline Model V: RFs+CACS+SSS & $0.62(0.39$ to 0.86$)$ & 0.18 & 0.45 & 0.19 (0.01 to 0.38$)$ & 0.20 & -0.01 \\
\hline Model VI: RFs+CACS+SIS & $0.56(0.33$ to 0.80$)$ & 0.15 & 0.41 & $0.14(-0.04$ to 0.34$)$ & 0.16 & -0.02 \\
\hline \multicolumn{7}{|c|}{ Compared with model II (RFs+CACS) } \\
\hline Model III: RFs+CACS+NIV & $-0.01(-0.16$ to 0.15$)$ & 0.07 & -0.07 & $0.07(-0.06$ to 0.21$)$ & 0.02 & 0.05 \\
\hline Model IV: RFs+CACS+Duke & $0.06(-0.07$ to 0.18$)$ & 0.10 & -0.04 & $0.06(-0.04$ to 0.14$)$ & 0.04 & 0.02 \\
\hline Model V: RFs+CACS+SSS & $0.09(-0.02$ to 0.21$)$ & 0.06 & 0.03 & $0.03(-0.07$ to 0.12$)$ & 0.01 & 0.02 \\
\hline Model VI: RFs+CACS+SIS & $0.02(-0.07$ to 0.13$)$ & 0.03 & -0.01 & $-0.02(-0.11$ to 0.06$)$ & -0.02 & 0.01 \\
\hline
\end{tabular}

cCTA indicates coronary computed tomographic angiography; FRS, Framingham Risk Score; NRI, net reclassification index; Cl, confidence interval; RFs, risk factors; CACS, coronary artery calcium score; Duke, Duke coronary artery disease prognostic index; NIV, number of involved vessels (categorized as none, nonobstructive coronary artery disease, obstructive 1-, 2-, 3-vessel disease or left main coronary artery disease); SSS, segment stenosis score; and SIS, segment involvement score.

*Framingham score risk factors were entered as a combined score in the FRS column and as individual variables in the Individual Risk Factors column. †NRI was calculated with 2.5 -y risk categories: (1) $0 \%$ to $<1.5 \%$; (2) $1.5 \%$ to $<5 \%$; and (3) $\geq 5 \%$.

Although not recommended by current guidelines, ${ }^{21,29}$ a few early reports have emerged evaluating the use of cCTA for risk stratification in asymptomatic high-risk individuals. ${ }^{13-17}$ However, the prognostic implication of occult CAD was not addressed adequately because of a very low rate of hard events (death or nonfatal MI). ${ }^{33}$ In addition, the value of cCTA to predict mortality could not be evaluated because of small study samples, and evaluation of cCTA compared with CACS for the prediction of cardiac events was not performed. ${ }^{34}$

\section{Prognostic Value of cCTA in Asymptomatic Individuals}

To our knowledge, this is the first registry analysis that evaluates the additive contribution of cCTA-defined CAD compared with risk factors and CACS in a large cohort without chest pain syndrome. Although the overall prevalence of obstructive CAD was generally low, our prognostic models nevertheless revealed an independent prediction of cCTA-defined CAD for incident mortality and composite outcome. However, the ability of these findings to improve risk stratification for the prediction of all-cause mortality beyond information derived from CACS was not observed. Although the cCTA showed a statistically significant likelihood ratio test when it was added to CACS plus risk factors for the composite outcome, the increments of $\mathrm{C}$ statistics and NRI of cCTA were modest (at best, they were 0.03 and 0.09 , respectively), whereas the increments of $\mathrm{C}$ statistics and NRI were obvious when CACS was added to Framingham risk factors alone (at best, they were 0.12 and 0.62 , respectively). When the potential population-based radiation burden, use of iodinated contrast, and greater cost of cCTA over CACS are considered, the evidence that cCTA offered in this study is not enough to justify the use of cCTA for risk stratification in a population without chest pain syndrome. 
The underlying reasons that cCTA demonstrates low incremental prognostic value over models incorporating CACS and Framingham risk factors necessitate discussion. Our present study evaluated stenosis severity as well as overall coronary artery plaque burden, accounting for location and extent of subtended myocardium. Although the ability of these findings to improve risk stratification for the prediction of all-cause mortality beyond information derived from CACS was not observed, cCTA offered minimal statistical improvement in risk prediction for a composite end point of death and MI. It appears that the added risk prediction of cCTA is driven largely by the risk of future MI. cCTA offers a potential diagnostic advantage over CACS, given the contrast enhancement and ensuing ability to identify atherosclerotic plaque components beyond calcified plaque, including fibrous, fibrolipoid, and lipoid plaque. ${ }^{35,36}$ These plaque characteristics have been related to myocardial ischemia and incident MI for symptomatic patients with suspected CAD. ${ }^{37-39}$ In this regard, the added benefit of cCTA over CACS for the prediction of MI may be related to the detection of noncalcified plaque by cCTA in current analyses. Therefore, future studies evaluating the totality of plaque characteristics may be useful for determining the role of noncalcified plaque for risk stratification in individuals without chest pain syndrome.

Furthermore, the calcified atherosclerotic plaque burden indicated by CACS may have an intrinsically greater prognostic value in a population without chest pain syndrome than in symptomatic patients. In symptomatic patients, identification of "lesions of interest" (ie, high-grade stenoses responsible for symptoms of CHD) is a major goal, and identification of these lesions is important for prognosticating future events. Conversely, in a population without chest pain, atherosclerosis evaluation may be more useful to identify "patients of interest" or individuals with coronary plaque that increases the likelihood of incident CHD events. Although CACS is incapable of imaging the severity of luminal stenoses, it is nevertheless an excellent surrogate marker for total plaque burden of individuals and unstable plaques. ${ }^{40,41}$ Therefore, despite its inability to directly visualize the coronary artery, CACS provides robust prognostic information within a population without chest pain for which the visualization of coronary artery luminal stenosis is not additive.

\section{Study Limitations}

This study is not without limitations. First, the study population was a subset of the CONFIRM registry with the potential for selection and individual site-related biases potentially operating herein. However, we attempted to minimize these potential biases by using standardized data definitions and inclusion of sites only where cCTA has been incorporated into general clinical care and where performance and interpretation of cCTA are led by individuals with adequate proficiency. Additionally, the primary outcome of our study was all-cause mortality, with the specific cause of death unavailable. The lack of cardiac-specific causes may result in variable prediction models. However, the use of all-cause mortality has the advantage of minimizing misclassification of causality. ${ }^{42}$ Furthermore, given the relatively low rate of adverse events, it remains possible that larger studies with longer follow-up may identify a potential value of cCTA for risk prediction in this low-risk cohort without chest pain syndrome.

\section{Conclusions}

In a large international multicenter study of individuals without chest pain syndrome, the additional risk-predictive advantage by cCTA is not clinically meaningful compared with a risk model based on CACS. Therefore, at present, the application of cCTA for risk assessment of individuals without chest pain syndrome should not be justified.

\section{Disclosures}

Dr Achenbach has received grant support from Siemens and Bayer Schering Pharma and is a consultant for Servier. Dr Al-Mallah has received support from the American Heart Association, Blue Cross Blue Shield Foundation of Michigan, and Astellas. Dr Budoff has received modest compensation from the speakers bureau of GE Healthcare. Dr Chow has received research and fellowship support from GE Healthcare and research support from Pfizer and AstraZeneca and educational support from TeraRecon. Dr Hausleiter has received research support from Siemens Medical Systems. Dr Maffei has received grant support from GE Healthcare. Dr Kaufmann has received institutional research support from GE Healthcare and grant support from the Swiss National Science Foundation. Dr Cademartiri has received grant support from GE Healthcare and Servier. Dr Raff has received grant support from Siemens, Blue Cross Blue Shield Blue Care of Michigan, and Bayer Pharma. Dr Chinnaiyan has received grant support from Bayer Pharma and Blue Cross Blue Shield Blue Care of Michigan. A.M. Dunning has received grant support from Clinical Translational Science Center. Dr Min has received modest compensation from the speakers bureau and medical advisory board and significant research support from GE Healthcare. The other authors report no conflicts.

\section{References}

1. Gibbons RJ, Jones DW, Gardner TJ, Goldstein LB, Moller JH, Yancy CW. The American Heart Association's 2008 statement of principles for healthcare reform. Circulation. 2008;118:2209-2218.

2. Lauer MS. Screening asymptomatic subjects for subclinical atherosclerosis: not so obvious. J Am Coll Cardiol. 2010;56:106-108.

3. Shah PK. Screening asymptomatic subjects for subclinical atherosclerosis: can we, does it matter, and should we? J Am Coll Cardiol. 2010;56: 98-105.

4. Greenland P, Alpert JS, Beller GA, Benjamin EJ, Budoff MJ, Fayad ZA, Foster E, Hlatky MA, Hodgson JM, Kushner FG, Lauer MS, Shaw LJ, Smith SC Jr, Taylor AJ, Weintraub WS, Wenger NK, Jacobs AK, Anderson JL, Albert N, Buller CE, Creager MA, Ettinger SM, Guyton RA, Halperin JL, Hochman JS, Nishimura R, Ohman EM, Page RL, Stevenson WG, Tarkington LG, Yancy CW. 2010 ACCF/AHA guideline for assessment of cardiovascular risk in asymptomatic adults: a report of the American College of Cardiology Foundation/American Heart Association Task Force on Practice Guidelines. J Am Coll Cardiol. 2010;56: e50-e103

5. Greenland P, LaBree L, Azen SP, Doherty TM, Detrano RC. Coronary artery calcium score combined with Framingham score for risk prediction in asymptomatic individuals. JAMA. 2004;291:210-215.

6. Raggi P, Gongora MC, Gopal A, Callister TQ, Budoff M, Shaw LJ. Coronary artery calcium to predict all-cause mortality in elderly men and women. J Am Coll Cardiol. 2008;52:17-23.

7. Budoff MJ, Shaw LJ, Liu ST, Weinstein SR, Mosler TP, Tseng PH, Flores FR, Callister TQ, Raggi P, Berman DS. Long-term prognosis associated with coronary calcification: observations from a registry of 25,253 patients. J Am Coll Cardiol. 2007;49:1860-1870.

8. Detrano R, Guerci AD, Carr JJ, Bild DE, Burke G, Folsom AR, Liu K, Shea S, Szklo M, Bluemke DA, O'Leary DH, Tracy R, Watson K, Wong ND, Kronmal RA. Coronary calcium as a predictor of coronary events in four racial or ethnic groups. N Engl J Med. 2008;358:1336-1345. 
9. Erbel R, Mohlenkamp S, Moebus S, Schmermund A, Lehmann N, Stang A, Dragano N, Gronemeyer D, Seibel R, Kalsch H, Brocker-Preuss M, Mann K, Siegrist J, Jockel KH. Coronary risk stratification, discrimination, and reclassification improvement based on quantification of subclinical coronary atherosclerosis: the Heinz Nixdorf Recall Study. $J$ Am Coll Cardiol. 2010;56:1397-1406.

10. Polonsky TS, McClelland RL, Jorgensen NW, Bild DE, Burke GL, Guerci AD, Greenland P. Coronary artery calcium score and risk classification for coronary heart disease prediction. JAMA. 2010;303: $1610-1616$.

11. Meijboom WB, van Mieghem CA, Mollet NR, Pugliese F, Weustink AC, van Pelt N, Cademartiri F, Nieman K, Boersma E, de Jaegere P, Krestin GP, de Feyter PJ. 64-Slice computed tomography coronary angiography in patients with high, intermediate, or low pretest probability of significant coronary artery disease. J Am Coll Cardiol. 2007;50:1469-1475.

12. Min JK, Shaw LJ, Berman DS. The present state of coronary computed tomography angiography: a process in evolution. $\mathrm{J} \mathrm{Am} \mathrm{Coll} \mathrm{Cardiol.}$ 2010;55:957-965.

13. Nucifora G, Schuijf JD, van Werkhoven JM, Jukema JW, Djaberi R, Scholte AJ, de Roos A, Schalij MJ, van der Wall EE, Bax JJ. Prevalence of coronary artery disease across the Framingham risk categories: coronary artery calcium scoring and MSCT coronary angiography. J Nucl Cardiol. 2009;16:368-375.

14. Djaberi R, Schuijf JD, Boersma E, Kroft LJM, Pereira AM, Romijn JA, Scholte AJ, Jukema JW, Bax JJ. Differences in atherosclerotic plaque burden and morphology between type 1 and 2 diabetes as assessed by multislice computed tomography. Diabetes Care. 2009;32:1507-1512.

15. Kornowski R, Bachar GN, Dvir D, Fuchs S, Atar E. Angiographic findings and clinical outcomes in asymptomatic patients with severe obstructive atherosclerosis on computed tomography angiography. Isr Med Assoc J. 2008;10:627-633.

16. Zeina A, Odeh M, Rosenschein U, Zaid G, Barmeir E. Coronary artery disease among asymptomatic diabetic and nondiabetic patients undergoing coronary computed tomography angiography. Coronary Artery Dis. 2008;19:37.

17. Cho I, Min HS, Chun EJ, Park SK, Choi Y, Blumenthal RS, Rivera JJ, Nasir K, Kim YJ, Sohn DW, Oh BH, Park YB, Chang HJ. Coronary atherosclerosis detected by coronary $\mathrm{CT}$ angiography in asymptomatic subjects with early chronic kidney disease. Atherosclerosis. 2010;208: 406-411.

18. Min JK, Dunning A, Lin FY, Achenbach S, Al-Mallah MH, Berman DS, Budoff MJ, Cademartiri F, Callister TQ, Chang HJ, Cheng V, Chinnaiyan KM, Chow B, Delago A, Hadamitzky M, Hausleiter J, Karlsberg RP, Kaufmann P, Maffei E, Nasir K, Pencina MJ, Raff GL, Shaw LJ, Villines TC. Rationale and design of the CONFIRM (Coronary CT Angiography Evaluation for Clinical Outcomes: An International Multicenter) registry. J Cardiovasc Comput Tomogr. 2011;5:84-92.

19. Chow BJW, Small G, Yam Y, Chen L, Achenbach S, Al-Mallah M, Berman DS, Budoff MJ, Cademartiri F, Callister TQ, Chang H-J, Cheng V, Chinnaiyan KM, Delago A, Dunning A, Hadamitzky M, Hausleiter J, Kaufmann P, Lin F, Maffei E, Raff GL, Shaw LJ, Villines TC, Min JK. Incremental prognostic value of cardiac computed tomography in coronary artery disease using CONFIRM: clinical perspective. Circ Cardiovasc Imaging. 2011;4:463-472.

20. Hendel RC, Patel MR, Kramer CM, Poon M, Carr JC, Gerstad NA, Gillam LD, Hodgson JM, Kim RJ, Lesser JR, Martin ET, Messer JV, Redberg RF, Rubin GD, Rumsfeld JS, Taylor AJ, Weigold WG, Woodard PK, Brindis RG, Douglas PS, Peterson ED, Wolk MJ, Allen JM. ACCF/ ACR/SCCT/SCMR/ASNC/NASCI/SCAI/SIR 2006 appropriateness criteria for cardiac computed tomography and cardiac magnetic resonance imaging: a report of the American College of Cardiology Foundation Quality Strategic Directions Committee Appropriateness Criteria Working Group, American College of Radiology, Society of Cardiovascular Computed Tomography, Society for Cardiovascular Magnetic Resonance, American Society of Nuclear Cardiology, North American Society for Cardiac Imaging, Society for Cardiovascular Angiography and Interventions, and Society Of Interventional Radiology. J Am Coll Cardiol. 2006;48:1475-1497.

21. Mark DB, Berman DS, Budoff MJ, Carr JJ, Gerber TC, Hecht HS, Hlatky MA, Hodgson JM, Lauer MS, Miller JM, Morin RL, Mukherjee D, Poon M, Rubin GD, Schwartz RS. ACCF/ACR/AHA/NASCI/SAIP/ SCAI/SCCT 2010 expert consensus document on coronary computed tomographic angiography: a report of the American College of Cardiology Foundation Task Force on Expert Consensus Documents. Circulation. 2010;121: $2509-2543$.
22. Agatston AS, Janowitz WR, Hildner FJ, Zusmer NR, Viamonte M Jr, Detrano R. Quantification of coronary artery calcium using ultrafast computed tomography. J Am Coll Cardiol. 1990;15:827-832.

23. Min JK, Shaw LJ, Devereux RB, Okin PM, Weinsaft JW, Russo DJ, Lippolis NJ, Berman DS, Callister TQ. Prognostic value of multidetector coronary computed tomographic angiography for prediction of all-cause mortality. J Am Coll Cardiol. 2007;50:1161-1170.

24. Vickers A, Cronin A, Begg C. One statistical test is sufficient for assessing new predictive markers. BMC Med Res Method. 2011;11:13.

25. Pencina MJ, D'Agostino RB. Overall C as a measure of discrimination in survival analysis: model specific population value and confidence interval estimation. Stat Med. 2004;23:2109-2123.

26. Harrell FE Jr, Lee KL, Mark DB. Multivariable prognostic models: issues in developing models, evaluating assumptions and adequacy, and measuring and reducing errors. Stat Med. 1996;15:361-387.

27. Steyerberg EW, Pencina MJ. Reclassification calculations for persons with incomplete follow-up. Ann Intern Med. 2010;152:195-196, author reply 196-197.

28. Pencina MJ, D’Agostino RB Sr, Steyerberg EW. Extensions of net reclassification improvement calculations to measure usefulness of new biomarkers. Stat Med. 2011;30:11-21.

29. Taylor AJ, Cerqueira M, Hodgson JM, Mark D, Min J, O'Gara P, Rubin GD, Kramer CM, Berman D, Brown A, Chaudhry FA, Cury RC, Desai MY, Einstein AJ, Gomes AS, Harrington R, Hoffmann U, Khare R, Lesser J, McGann C, Rosenberg A, Schwartz R, Shelton M, Smetana GW, Smith SC Jr. ACCF/SCCT/ACR/AHA/ASE/ASNC/NASCI/ SCAI/SCMR 2010 appropriate use criteria for cardiac computed tomography: a report of the American College of Cardiology Foundation Appropriate Use Criteria Task Force, the Society of Cardiovascular Computed Tomography, the American College of Radiology, the American Heart Association, the American Society of Echocardiography, the American Society of Nuclear Cardiology, the North American Society for Cardiovascular Imaging, the Society for Cardiovascular Angiography and Interventions, and the Society for Cardiovascular Magnetic Resonance. J Am Coll Cardiol. 2010;56:1864-1894.

30. Perrone-Filardi P, Achenbach S, Mohlenkamp S, Reiner Z, Sambuceti G, Schuijf JD, Van der Wall E, Kaufmann PA, Knuuti J, Schroeder S, Zellweger MJ. Cardiac computed tomography and myocardial perfusion scintigraphy for risk stratification in asymptomatic individuals without known cardiovascular disease: a position statement of the Working Group on Nuclear Cardiology and Cardiac CT of the European Society of Cardiology. Eur Heart J. 2011;32:1986-1993, 1993a, 1993b.

31. Achenbach S, Raggi P. Imaging of coronary atherosclerosis by computed tomography. Eur Heart J. 2010;31:1442-1448.

32. Ostrom MP, Gopal A, Ahmadi N, Nasir K, Yang E, Kakadiaris I, Flores F, Mao SS, Budoff MJ. Mortality incidence and the severity of coronary atherosclerosis assessed by computed tomography angiography. $\mathrm{J} \mathrm{Am}$ Coll Cardiol. 2008;52:1335-1343.

33. Choi EK, Choi SI, Rivera JJ, Nasir K, Chang SA, Chun EJ, Kim HK, Choi DJ, Blumenthal RS, Chang HJ. Coronary computed tomography angiography as a screening tool for the detection of occult coronary artery disease in asymptomatic individuals. J Am Coll Cardiol. 2008;52: 357-365.

34. Hadamitzky M, Meyer T, Hein F, Bischoff B, Martinoff S, Schomig A, Hausleiter J. Prognostic value of coronary computed tomographic angiography in asymptomatic patients. Am J Cardiol. 2010;105: $1746-1751$.

35. Carrascosa PM, Capunay CM, Garcia-Merletti P, Carrascosa J, Garcia MF. Characterization of coronary atherosclerotic plaques by multidetector computed tomography. Am J Cardiol. 2006;97:598-602.

36. Pohle K, Achenbach S, Macneill B, Ropers D, Ferencik M, Moselewski F, Hoffmann U, Brady TJ, Jang IK, Daniel WG. Characterization of non-calcified coronary atherosclerotic plaque by multi-detector row $\mathrm{CT}$ : comparison to IVUS. Atherosclerosis. 2007;190:174-180.

37. Shmilovich H, Cheng VY, Tamarappoo BK, Dey D, Nakazato R, Gransar H, Thomson LE, Hayes SW, Friedman JD, Germano G, Slomka PJ, Berman DS. Vulnerable plaque features on coronary $\mathrm{CT}$ angiography as markers of inducible regional myocardial hypoperfusion from severe coronary artery stenoses. Atherosclerosis. 2011;219:588-595.

38. van Werkhoven JM, Schuijf JD, Gaemperli O, Jukema JW, Kroft LJ, Boersma E, Pazhenkottil A, Valenta I, Pundziute G, de Roos A, van der Wall EE, Kaufmann PA, Bax JJ. Incremental prognostic value of multi-slice computed tomography coronary angiography over coronary artery calcium scoring in patients with suspected coronary artery disease. Eur Heart J. 2009;30:2622-2629. 
39. Lin F, Shaw LJ, Berman DS, Callister TQ, Weinsaft JW, Wong FJ, Szulc M, Tandon V, Okin PM, Devereux RB, Min JK. Multidetector computed tomography coronary artery plaque predictors of stress-induced myocardial ischemia by SPECT. Atherosclerosis. 2008;197:700-709.

40. Rumberger JA. Coronary artery calcification: "empty your cup." Am Heart J. 1999;137:774-776.
41. Doherty TM, Detrano RC, Mautner SL, Mautner GC, Shavelle RM. Coronary calcium: the good, the bad, and the uncertain. Am Heart J. 1999; 137:806-814.

42. Lauer MS, Blackstone EH, Young JB, Topol EJ. Cause of death in clinical research: time for a reassessment? J Am Coll Cardiol. 1999;34:618-620.

\section{CLINICAL PERSPECTIVE}

This is the first registry analysis to evaluate the additive contribution of coronary computed tomographic angiography (cCTA)-defined coronary artery disease compared with clinical risk factors and coronary artery calcium score in a large international multicenter cohort of individuals without chest pain syndrome. Although the overall prevalence of obstructive coronary artery disease was generally low, our prognostic models revealed an independent prediction of cCTA-defined coronary artery disease for incident mortality and the composite outcome of all-cause mortality and nonfatal myocardial infarction. However, the ability of these findings to improve risk stratification for the prediction of all-cause mortality beyond information derived from coronary artery calcium score was not observed. cCTA offered minimal statistical improvement in risk prediction and reclassification for a composite end point of death and myocardial infarction. Given the ability of cCTA to identify atherosclerotic plaque components beyond calcified plaque, including fibrous, fibrolipoid, and lipoid plaque, future studies examining these plaque characteristics in asymptomatic individuals undergoing cCTA and coronary artery calcium score may be useful to further investigate the present study findings. At present, however, the application of cCTA for risk assessment of individuals without chest pain syndrome beyond coronary artery calcium score does not appear justified. 


\section{SUPPLEMENTAL MATERIAL}

\section{Supplemental Methods}

\section{Coronary Artery Plaque Scores}

Coronary artery plaque scores were calculated for overall plaque burden by extent and severity of CAD using a modified Duke prognostic CAD score, segment stenosis score (SSS) and segment-involvement score (SIS), as we have previously described. . ${ }^{1}$

\section{\# Modified Duke prognostic CAD score}

Modified Duke prognostic CAD index was used to assess prognosis in patients with $<50 \%$ stenosis. Individuals were assigned to the highest disease category, and categorized as following subsets: 1 ) <50\% stenosis; 2 ) $\geq 2$ stenoses 30\% to 49\% (including 1 artery with proximal disease or 1 vessel with $50 \%$ to $69 \%$ stenosis; 3 ) 2 stenoses $50 \%$ to $69 \%$ or 1 vessel with $\geq 70 \%$ stenosis; 4 ) 3 stenoses $50 \%$ to $69 \%$ or 2 vessels with $\geq 70 \%$ stenosis or proximal left anterior descending stenosis $\geq 70 \%$; 5) 3 vessels $\geq 70 \%$ stenoses or 2 vessels $\geq 70 \%$ stenosis with proximal left anterior descending; and 6 ) left main stenosis $\geq 50 \%$.

\section{\# Segment stenosis score (SSS)}

The SSS was employed as a measure of overall coronary artery plaque extent. Each individual coronary segment of patient was graded as no plaque to severe plaque (scores from 0 to 3 ) based on extent of obstruction of coronary luminal diameter. After that, the extent scores of all 16 segments were summed to yield a total score ranging from 0 to 48.

\section{\# Segment involvement score (SIS)}

The SIS was calculated as a measure of overall coronary artery plaque distribution. The SIS was calculated by summation of the absolute number of coronary artery segments with plaque, irrespective of the degree of luminal stenosis within each segment (scores from 0 to 16). 


\section{Prospective form net reclassification improvement (NRI) ${ }^{2}$}

The NRI measures the degree of correct movement in categories or probability values between subjects who experienced and did not experience events. Consider a situation in which predicted probabilities of a given event of interest come from two different risk prediction algorithms denoted here as 'new' (ex. FRS+CACS) and 'old' (ex. FRS alone). Divide the predicted probabilities based on two algorithms (ex. FRS alone vs FRS+CACS) into a set of clinically meaningful ordinal categories of absolute risk and then cross-tabulate these two classifications. Define upward movement (up) as a change into higher category based on the new algorithm (ex. FRS+CACS) and downward movement (down) as a change in the opposite direction. The NRI is defined as:

$$
\mathrm{NRI}=P(\text { up|event })-P(\text { down|event })+P(\text { down|non-event })-P \text { (up|non-event) }
$$

Using the Bayes rule we rewrite formula (1) in a different but equivalent form:

$$
\mathrm{NRI}=\frac{(P(\text { event } \mid \text { up })-P(\text { event })) \cdot P(\text { up })+(P(\text { event })-P(\text { event } \mid \text { down })) \cdot P(\text { down })}{P(\text { event }) \cdot(1-P(\text { event }))}
$$

The latter form gives a prospective interpretation and allows the substitution of relevant Kaplan-Meier rates in place of simple proportions and thus accounts for premature discontinuations. 
Supplement Table1. Risk of Composite Outcome of Non-fatal Myocardial Infarction and All-Cause Mortality According to FRS,

\section{CACS, and CCTA Models}

\begin{tabular}{|c|c|c|c|c|c|c|c|c|}
\hline \multirow[b]{2}{*}{ Variable } & \multicolumn{4}{|c|}{ Unadjusted Model } & \multicolumn{4}{|c|}{ Adjusted for Individual Framingham RFs* } \\
\hline & No & HR & $95 \% \mathrm{Cl}$ & $P$ Value & No & HR & $95 \% \mathrm{Cl}$ & $P$ Value \\
\hline FRS model & 4,304 & & & $0.019^{\dagger}$ & & & & \\
\hline $\operatorname{Low}(<10)$ & 2,200 & 1.00 & & & & & & \\
\hline Low intermediate(10-15) & 1,004 & 1.38 & $0.75-2.54$ & 0.294 & & & NA & \\
\hline High intermediate(16-20) & 407 & 1.63 & $0.74-3.58$ & 0.228 & & & & \\
\hline High(>20) & 693 & 2.01 & $1.10-3.69$ & 0.024 & & & & \\
\hline CACS model & 3,640 & & & $<0.001^{\dagger}$ & 3,217 & & & $<0.001^{\dagger}$ \\
\hline 0 & 1,773 & 1.00 & & & 1,581 & 1.00 & & \\
\hline $1-100$ & 920 & 1.55 & $0.73-3.28$ & 0.252 & 811 & 1.10 & $0.50-2.41$ & 0.809 \\
\hline $101-400$ & 546 & 3.14 & $1.53-6.44$ & 0.002 & 472 & 2.16 & $1.02-4.58$ & 0.045 \\
\hline$>400$ & 401 & 6.18 & $3.20-11.94$ & $<0.001$ & 353 & 3.82 & $1.85-7.88$ & $<0.001$ \\
\hline \multicolumn{9}{|l|}{ cCTA models } \\
\hline Presence of obstructive CAD & 4,870 & & & & 4,304 & & & \\
\hline None or non-obstructive CAD & 3,912 & 1.00 & & & 3,467 & 1.00 & & \\
\hline Obstructive CAD & 958 & & & $<0.001$ & 837 & 2.48 & $1.52-4.05$ & $<.0001$ \\
\hline No of involved vessels & 4,870 & & & $<0.001^{\dagger}$ & 4,304 & & & $<0.001^{\dagger}$ \\
\hline None & 1,881 & 1.00 & & & 1,688 & 1.0 & & \\
\hline Non-obstructive CAD & 2,031 & 2.23 & $1.16-4.28$ & 0.017 & 1,779 & 1.66 & $0.83-3.31$ & 0.153 \\
\hline 1-VD & 605 & 2.99 & $1.67-6.56$ & 0.006 & 523 & 2.11 & $0.92-4.86$ & 0.078 \\
\hline 2-VD & 236 & 8.35 & $3.80-18.31$ & $<0.001$ & 208 & 5.91 & $2.53-13.80$ & $<0.001$ \\
\hline 3-VD or left main CAD & 117 & 11.27 & $4.67-27.20$ & $<0.001$ & 106 & 7.11 & $2.73-18.51$ & $<0.001$ \\
\hline Duke index (per score increased) & 4,870 & 1.41 & $1.27-1.57$ & $<0.001^{\dagger}$ & 4,304 & 1.33 & $1.17-1.50$ & $<0.001^{\dagger}$ \\
\hline SSS (per segment severity) & 4,870 & 1.11 & $1.08-1.15$ & $<0.001^{\dagger}$ & 4,304 & 1.09 & $1.05-1.13$ & $<0.001^{\dagger}$ \\
\hline SIS (per segement involved) & 4,870 & 1.18 & $1.11-1.26$ & $<0.001^{\dagger}$ & 4,304 & 1.14 & $1.06-1.22$ & $<0.001^{\dagger}$ \\
\hline
\end{tabular}

FRS indicates Framingham risk score; $\mathrm{CAD}$, coronary artery disease; HR, hazard ratio; $\mathrm{Cl}$, confidence interval; CACS, coronary artery calcium score; 
cCTA, coronary computed tomographic angiography; VD, vessel disease; No, number; Duke score, Duke CAD prognostic index; SSS, segment stenosis score; SIS, segment involvement score; NA, not applicable

* Individual Framingham risk factors included age, gender, hypertension, diabetes, current smoking, and dyslipidemia.

${ }^{\dagger} P$ Value for trend 
Supplement Table 2. Comparison of performance of CACS and CCTA in predicting 2.5-Year Risk of All-Cause Mortality and Composite Outcome of All-Cause Mortality and Non-Fatal MI using Likelihood Ratio Tests.

\begin{tabular}{|c|c|c|c|c|}
\hline \multirow{2}{*}{ Model } & \multicolumn{2}{|c|}{ FRS* } & \multicolumn{2}{|c|}{ Individual Risk Factors* } \\
\hline & Likelihood Ratio & P-Value & Likelihood Ratio & P-Value \\
\hline \multicolumn{5}{|c|}{ All-cause mortality $(\mathrm{N}=3,900)$} \\
\hline \multicolumn{5}{|l|}{ Compared with Model I (RFs only) } \\
\hline Model II: RFs + CACS & 1128.35 & $<0.001$ & 1146.02 & $<0.001$ \\
\hline Model III: RFS + CACS+NIV & 1132.23 & $<0.001$ & 1149.58 & $<0.001$ \\
\hline Model IV: RFs + CACS+ Duke & 1131.37 & $<0.001$ & 1149.58 & $<0.001$ \\
\hline Model V: RFs + CACS+ SSS & 1131.37 & $<0.001$ & 1149.58 & $<0.001$ \\
\hline Model VI: RFs + CACS+ SIS & 1128.84 & $<0.001$ & 1146.02 & $<0.001$ \\
\hline \multicolumn{5}{|c|}{ Compared with Model II (FRS+CACS) } \\
\hline Model III: RFs + CACS+ NIV & 3.88 & 0.423 & 3.557 & 0.469 \\
\hline Model IV: RFs + CACS+ Duke & 3.02 & 0.082 & 3.557 & 0.059 \\
\hline Model V: RFs + CACS+ SSS & 1.64 & 0.200 & 3.557 & 0.059 \\
\hline Model VI: RFS + CACS+ SIS & 0.49 & 0.482 & 0.001 & 0.975 \\
\hline \multicolumn{5}{|c|}{ Composite Outcome of All-Cause Mortality and Non-Fatal MI $(N=3,217)$} \\
\hline \multicolumn{5}{|l|}{ Compared with Model I (RF only) } \\
\hline Model II: RFs + CACS & 240.16 & $<0.001$ & 247.25 & $<.0001$ \\
\hline Model III: RFs + CACS+NIV & 258.81 & $<0.001$ & 263.26 & $<.0001$ \\
\hline Model IV: RFs + CACS+ Duke & 250.80 & $<0.001$ & 254.24 & $<.0001$ \\
\hline Model V: RFS + CACS+ SSS & 250.58 & $<0.001$ & 254.17 & $<.0001$ \\
\hline Model VI: RFs + CACS+ SIS & 246.86 & $<0.001$ & 250.60 & $<.0001$ \\
\hline \multicolumn{5}{|c|}{ Compared with Model II (FRS+CACS) } \\
\hline Model III: RFs + CACS+NIV & 18.65 & $<0.001$ & 16.02 & 0.003 \\
\hline Model IV: RFs + CACS+ Duke & 10.65 & 0.001 & 7.00 & 0.008 \\
\hline Model V: RFS + CACS+ SSS & 10.42 & 0.001 & 6.92 & 0.009 \\
\hline Model VI: RFs + CACS+ SIS & 6.70 & 0.010 & 3.36 & 0.067 \\
\hline
\end{tabular}

CACS indicates coronary artery calcium score; CAD, coronary artery disease; CCTA, coronary computed tomographic angiography; CI, confidence interval; Duke, Duke CAD prognostic index; FRS, Framingham risk score; N, number of patients; NIV, number of involved vessels (categorized as none, non- 
obstructive CAD, obstructive 1-VD, 2-VD, 3-VD or left main CAD); RFs, Framingham risk factors; SIS, segment involvement score; SSS, segment stenosis score ;VD, vessel disease 


\section{Reference}

1. Min JK, Shaw LJ, Devereux RB, Okin PM, Weinsaft JW, Russo DJ, Lippolis NJ, Berman DS, Callister TQ. Prognostic value of multidetector coronary computed tomographic angiography for prediction of all-cause mortality. J Am Coll Cardiol. 2007;50:1161-1170

2. Pencina MJ, D'Agostino RB, Sr., Steyerberg EW. Extensions of net reclassification improvement calculations to measure usefulness of new biomarkers. Stat Med. 2011;30:11-21 